\title{
Donor site morbidity following free tissue transfer: A preliminary survey
}

\author{
James Mahoney MD FRCSC, Eric Kharaillah MD, Dimitri Drakos MD \\ St Michael's Hospital and the University of Toronto, Toronto, Ontario
}

\section{J Mahoney, E Kharaillah, D Drakos. Donor site morbidity following free tissue transfer: A preliminary survey. Can J Plast Surg 1998;6(2):85-88.}

Donor site morbidity is becoming an important factor in the measurement of reconstructive success following free tissue transfer. A grading system based on five criteria (cosmesis, functional loss, wound healing, iatrogenic injury and pain) has been devised to evaluate and compare different donor sites in a uniform fashion. Questionnaires were sent to microsurgeons across Canada and to a series of patients asking them to report on their experiences with donor site morbidity. Completed questionnaires from 43 patients and 29 surgeons revealed that overall, donor site morbidity is low. This study represents a retrospective survey of the donor site of various free tissue transfers and highlights potential problems of several frequently used free flaps. The radial forearm flap had the highest morbidity, especially with regard to wound healing and cosmesis. Suggestions to improve studies in this area further are made.

Key Words: Donor site, Free flap, Morbidity, Outcome

\section{Morbidité du site donneur après une greffe de tissu libre : revue préliminaire}

RÉSUMÉ : La morbidité au site donneur devient un important facteur à entrer en ligne de compte dans l'évaluation de la réussite d'une intervention reconstructive après une greffe de tissu libre. On a mis sur pied un système de gradation fondé sur cinq critères (cosmésie, perte fonctionnelle, cicatrisation de la plaie, blessure iatrogène et douleur) afin d'évaluer et de comparer de façon uniforme les différents sites donneurs. Des questionnaires ont été expédiés aux microchirurgiens de partout au Canada et à une série de patients pour leur demander de parler de leur expérience au chapitre de la morbidité des sites donneurs. Les questionnaires dûment complétés de 43 patients et de 29 chirurgiens ont révélé que, de façon globale, le taux de morbidité associé au site donneur est faible. L'étude représente une enquête rétrospective sur les sites donneurs de différentes greffes de tissus libres et rappelle les problèmes potentiels de plusieurs lambeaux libres d'usage fréquent. Le lambeau radial, à l'avant-bras, a été celui qui s'est accompagné du plus fort taux de morbidité, surtout en ce qui a trait à la cicatrisation de la plaie et à la cosmésie. On formule ici quelques suggestions pour améliorer les études dans ce domaine.

$\mathrm{F}$ ee tissue transfer has rapidly developed into a mainstay of reconstructive surgery. Anatomical studies and their clinical application have led to a rapid increase in the number of safe and reliable flaps for transfer. Various tissue components from a variety of anatomical areas can provide the requirements for a potential recipient site. With success rates approaching $95 \%$ at the recipient site, attention is becoming focused on the functional and esthetic aspects of the reconstruction as a whole. Donor site morbidity is an integral part of this evaluation. The reconstructive surgeon should be able

Correspondence and reprints: Dr James Mahoney, St Michael's Hospital, 30 Bond Street, Toronto, Ontario M5B 1W8. Telephone 416-864-5385, fax 416-864-5888, e-mail james.mahoney@utoronto.ca to choose a flap that best fulfils the requirements of a given recipient site and minimizes the morbidity at the donor site. The purpose of this study was to evaluate the applicability of a grading system of donor sites in clinical practice and to survey specific problems with donor site complications from physicians' and patients' perspectives.

\section{MATERIALS AND METHODS}

A donor site evaluation system was devised based on five criteria: pain, cosmesis, iatrogenic injury, functional loss and local wound healing. Each category was assigned a value based on its perceived significance (Table 1). Of the five criteria, functional loss and pain were assigned a higher value of 4, cosmesis and wound healing were assigned a maximum 
TABLE 1

Criteria and subscales of the donor site evaluation system

\begin{tabular}{ll}
\hline Criterion & Score \\
\hline Cosmesis & \\
None (linear scar) & 0 \\
Minor (slight scar depression, hidden) & 1 \\
Moderate (spread scar, skin graft) & 2 \\
Major (digital loss, hernia) & 3 \\
Functional loss & \\
None & 0 \\
Minor (only demonstrable by some functional test) & 2 \\
Major (functional deficit) & 4 \\
Wound healing complications & \\
None & 0 \\
Minor (requires dressing beyond 14 days) & 1 \\
Moderate (secondary procedure or protection beyond & 2 \\
$\quad$ 28 days) & \\
Major (requires reoperation) & 3 \\
latrogenic injury & \\
None & \\
Minor (eg, neuroma, sensory deficit) & \\
Major (eg, fracture, paralysis, vascular injury) & 0 \\
None & 1 \\
\hline Major (narcotic or modified activity) & 2 \\
\hline & \\
\hline
\end{tabular}

score of 3 and iatrogenic injury was assigned a maximum score of 2. Subscales of each criteria were designed with descriptions for each assigned value. The maximum score is 16 .

In the first part of this study, a survey in the form of a questionnaire was sent to listed members of the Group for the Advancement of Microsurgery in Canada. Surgeons were asked to list their three most common free flaps and the most common and serious complications of each flap, and to estimate what percentage of their reported donor sites had problems with each of the five criteria. A total morbidity score was obtained by multiplying the score of each subscale of the criteria by its estimated frequency expressed as a percentage (Table 2) and adding the values of all of the criteria (maximum 1600). The sum was divided by 100 to give the score. The higher the value, the greater the relative donor site morbidity. The values were averaged to get a total score for each flap by all physicians. Each of the criteria was analyzed for each flap in a similar fashion. Data were entered into a graphical program and analyzed.

The second part involved all patients who had free flaps between January 1992 and January 1994 by one surgeon. A similar donor site questionnaire was sent to all patients, asking them to grade each of the five criteria for their flap. The questionnaires were completed by mail, by telephone interview or in person during a follow-up visit. Analysis of the
TABLE 2

Sample calculation of the criteria of pain

\begin{tabular}{lccc}
\hline & Flap 1 & Flap 2 & Flap 3 \\
\hline None & 30 & 70 & 90 \\
Minor & 60 & 30 & 10 \\
Major & 10 & 0 & 0 \\
\hline
\end{tabular}

Sample calculation for flap 1: $(0 \times 30=0)+(2 \times 60=120)+(4 \times 10=40)=160$ or 1.6. The value 0,2 or 4 is multiplied by the reported frequency as expressed as a percentage to give the total for pain (maximum 400/100=4)

TABLE 3

Most common and serious complications for the most commonly reported flaps

\begin{tabular}{lll}
\hline Free flap & \multicolumn{1}{c}{$\begin{array}{c}\text { Most common } \\
\text { complication }\end{array}$} & \multicolumn{1}{c}{$\begin{array}{c}\text { Most serious } \\
\text { complication }\end{array}$} \\
\hline Radial forearm & Incomplete graft take & Tendon exposure \\
Rectus & Abdominal bulge & Hernia \\
Fibula & Pain with ambulation & Chronic pain \\
\hline
\end{tabular}

questionnaires was performed in a similar fashion to that of the surgeons' questionnaires.

\section{RESULTS}

Twenty-nine microsurgeons across Canada completed and returned the questionnaire ( $49 \%$ completion rate). The three most common donor site areas were the radial forearm (22 surgeons), the rectus abdominis muscle flap (19 surgeons) and the fibula (16 surgeons). Other commonly used free flaps were the latissimus dorsi, gracilis and lateral arm. The most common complications were incomplete graft take (radial forearm), abdominal bulge (rectus) and pain (fibula). The most serious complications were tendon exposure (radial forearm), hernia (rectus) and chronic pain (fibula) (Table 3). Less frequent serious complications such as radius fracture and peroneal nerve palsy were also reported.

For the surgeons, the radial forearm site had the highest total donor morbidity score (4.1 of 16) followed by the latissimus dorsi, rectus and fibula, which had almost identical morbidity scores. The lateral arm and gracilis had the lowest total morbidities (Figure 1). Evaluation of specific criteria revealed the radial forearm flap as having the worst cosmesis (1.9 of three) followed by the latissimus dorsi, lateral arm, fibula and rectus, which had very similar scores. The gracilis was reported to have the best cosmesis. With respect to functional loss, the latissimus dorsi and rectus had the highest score ( 0.9 of four), followed by the radial forearm and the fibula. The gracilis and the lateral arm donor site received the lowest scores. With respect to pain the fibula ( 0.7 of 4 ), the rectus and the radial forearm had the highest scores in decreasing order, followed by the latissimus dorsi and the gracilis. The lateral arm donor site received the lowest score. Potential for iatrogenic injury was highest for the radial forearm flap (0.4 of two) followed by the lateral arm and the fib- 


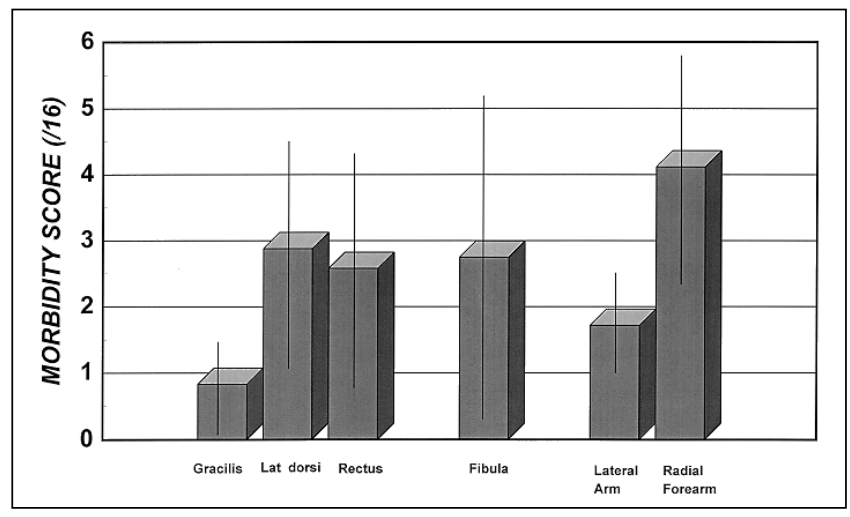

Figure 1) Total morbidity score for the most common flaps reported by physicians. Lat Latissimus

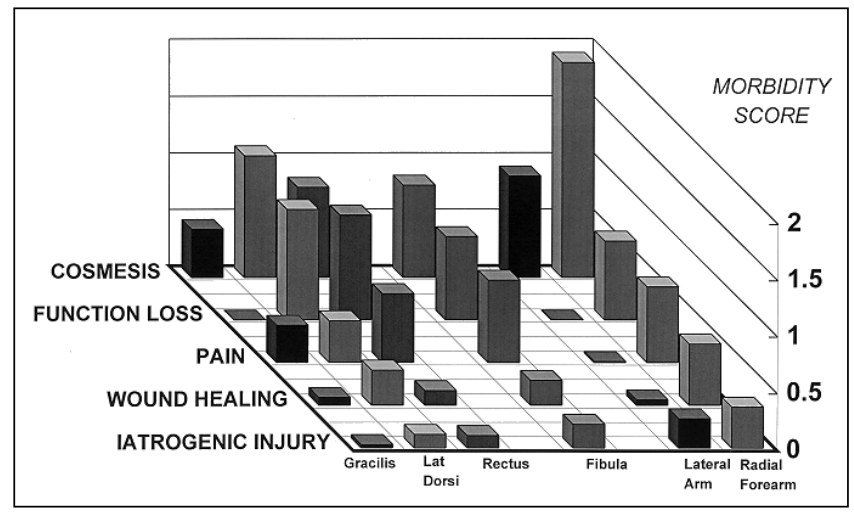

Figure 2) Morbidity for each of the criteria of the most common free flaps reported by physicians. Lat Latissimus

ula. Finally, the radial forearm flap received the highest score for wound healing ( 0.5 of three), while the gracilis and the lateral arm received the lowest scores (Figure 2).

A total of 70 patients with 77 free flaps of various types were studied. The average patient age was 40 years (range 22 to 77 years). Follow-up time ranged from six to 36 months, with an average of 19 months. Of 70 patients, 43 completed the questionnaire for a total of 49 free flaps ( 11 rectus, 14 radial forearm, nine lateral arm, 10 fibula and five latissimus dorsi); 27 patients were lost to follow-up. The radial forearm flap had the highest total morbidity score (3.6 of 16) - almost twice that of the other flaps. The lateral arm and latissimus dorsi scored in the middle, while the fibula and rectus flaps received the highest scores (Figure 3). Further analysis revealed that, with respect to cosmesis, wound healing and functional loss, the radial forearm had high morbidity scores. The latissimus dorsi also received high scores for cosmesis but received the lowest scores for functional loss, pain and iatrogenic injury. The fibula donor site had the best cosmesis (Figure 4).

\section{DISCUSSION}

In planning free tissue transfer, one not only must provide an optimal solution for the recipient site, but should also consider the potential morbidity of the donor site. A good donor

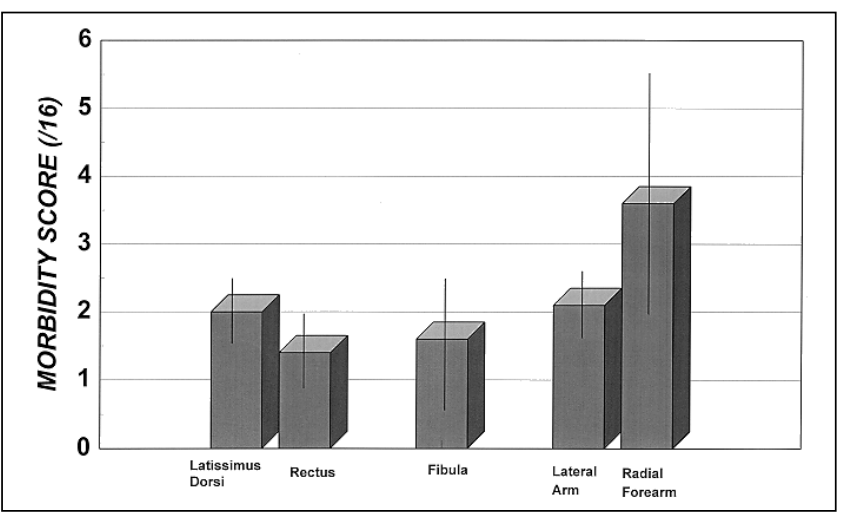

Figure 3) Total morbidity of the most commonl free flaps reported by patients

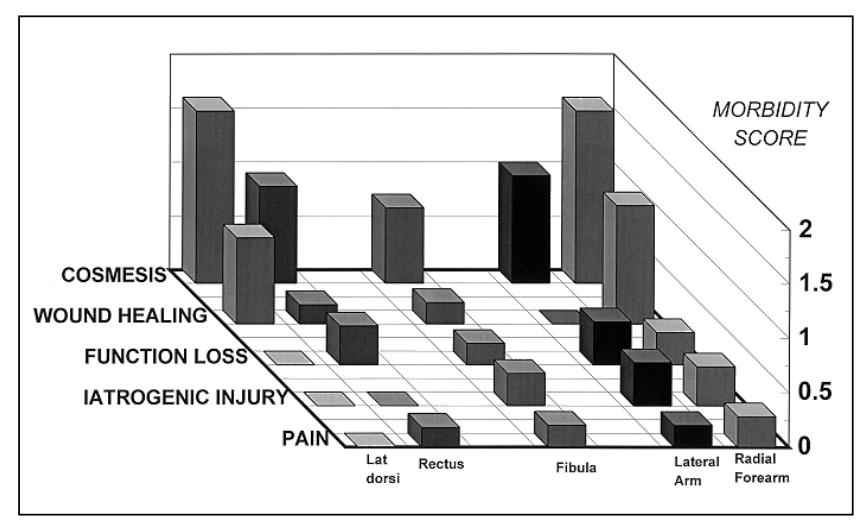

Figure 4) Morbidity for each of the criteria of the most commonly performed free flaps. Lat Latissimus

site from the physician's perspective may not be good from the patient's perspective. Donor site morbidity has received attention in the literature (1-5); however the majority of the reports on morbidity have been in articles on individual flaps. Early and late complications such as seroma, hematoma, wound dehiscence, incomplete graft take and a variety of functional disabilities have been described. No standard method to evaluate or grade donor site morbidity has been described.

The questionnaire used in the present study was developed to facilitate completion by physicians and patients. The data collected were subjective and qualitative, and were converted to numerical values to allow comparison of the flaps.

A prospective study to include other factors such as skin defect size, tissue composition and different treatment protocols for the same donor site are potential factors that can affect morbidity and should also be studied. This would allow more detailed scientific study with statistical analysis of data that are objective and validated.

Using the described grading system, we have identified similar problems with several common donor sites. Some are preventable but occur with significant frequency to warrant careful attention to maximize prevention. The radial forearm flap demonstrated the greatest donor site morbidity from both patients and physicians. This was especially true for 
both cosmesis and wound healing. Considerable attention has been paid in the literature concerning its treatment. Design of the flap with ulnar skin (6), pre-expansion of the donor site (7), V-Y advancement flaps (8) and pronator quadratus flaps (9) have been suggested and are applicable in certain circumstances. Emphasis has also been placed on meticulous preparation of the recipient bed with coverage of the exposed tendon or nerve and careful application of the skin graft dressing with immobilization for a period of three weeks (10). The lateral arm, also a fasciocutaneous flap, scored better than the radial forearm flap. One might choose this donor site with a better cosmesis and wound healing potential or a muscle flap and skin graft such as the gracilis, which had the lowest scores. As further advances are made in free tissue transfer, evaluation of the effect of different tissue composition (eg, free fibula with or without a skin paddle) may reveal an alternative. In the era of endoscopic surgery the apparent improved donor scar will also play a role in reducing morbidity, but evaluation of this technology is required to justify the additional cost and the potential increase in other complications. Applying a system that considers these factors will allow scientific comparison of the different aspects of free flap donor sites.

\section{REFERENCES}

1. Mahoney JL. Complications of free flap donor sites. Microsurgery 1995;16:437-44.

2. Deutinger M, Kuzbari R, Paternostro-sluza T, et al. Donor-site morbidity of the gracilis flap. Plast Reconstr Surg 1995;95:1240-4.

3. Anthony JP, Rawnsley JD, Benharin P, et al. Donor leg morbidity and function after fibula free flap mandible reconstruction. Plast Reconstr Surg 1995;96:146-52.

4. Colen SR, Shaw WW, McCarthy JG. Review of the morbidity of 300 free flap-donor sites. Plast Reconstr Surg 1986;77:948-53.

5. Hallock G. Complications of the free-flap donor sites from a community hospital perspective. J Reconstr Microsurg 1991;7:331-4.

6. Boorman JG, Brown JA, Sykes PJ. Morbidity in the forearm flap donor arm. Br J Plast Surg 1987;40:207-12.

7. Masser MR. The preexpanded radial free flap. Plast Reconstr Surg 1990;86:295-302.

8. Elliot D, Bardsley AF, Batchelor AG, Soutar DS. Direct closure of the radial forearm flap donor defect. Br J Plast Surg 1988;41:358-60.

9. Kupfer D, Lister G. The pronator qudratus muscle flap: Coverage of the oseteomized radius following elevation of the radial forearm flap. Plast Reconstr Surg 1992;90:1093-5.

10. McGregor AD. The free radial forearm flap - the management of the secondary defect. Br J Plast Surg 1987;40:83-5. 